\title{
Effects of age on the identification of emotions in facial expressions: A meta-analysis
}

\author{
Ana R Gonçalves ${ }^{\text {Corresp., }}{ }^{1}$ ， Carina Fernandes ${ }^{1,2,3}$ ， Rita Pasion ${ }^{1}$ ， Fernando Ferreira-Santos ${ }^{1}$, Fernando Barbosa ${ }^{1}$ \\ , João Marques-Teixeira ${ }^{1}$ \\ 1 \\ Laboratory of Neuropsychophysiology,Faculty of Psychology and Education Sciences, Universidade do Porto, Porto, Portugal \\ 2 Faculty of Medicine, Universidade do Porto, Porto, Portugal \\ Language Research Laboratory, Institute of Molecular Medicine, Faculty of Medicine, Universidade de Lisboa, Lisboa, Portugal \\ Corresponding Author: Ana R Gonçalves \\ Email address: a.s.ribeiro.g@gmail.com
}

Background. Emotion identification is a fundamental component of social cognition. Although it is well established that a general cognitive decline occurs with advancing age, the effects of age on emotion identification is still unclear. A meta-analysis by Ruffman and colleagues (2008) explored this issue, but much research has been published since then, reporting inconsistent findings.

Methods. To examine age differences in the identification of facial expressions of emotion, we conducted a meta-analysis of 24 empirical studies ( $N=1033$ older adults, $N=1135$ younger adults) published after 2008. Additionally, a meta-regression analysis was conducted to identify potential moderators.

Results. Results show that older adults less accurately identify facial expressions of anger, sadness, fear, surprise, and happiness compared to younger adults, strengthening the results obtained by Ruffman et al. (2008). However, meta-regression analyses indicate that effect sizes are moderated by sample characteristics and stimulus features. Importantly, the estimated effect size for the identification of fear and disgust increased for larger differences in the number of years of formal education between the two groups.

Discussion: We discuss several factors that might explain the age-related differences in emotion identification and suggest how brain changes may account for the observed pattern. Furthermore, moderator effects are interpreted and discussed. 
1 Effects of age on the identification of emotions in facial expressions: a meta-analysis

2 Ana R. Gonçalves ${ }^{1}$, Carina Fernandes ${ }^{1,2,3}$, Rita Pasion ${ }^{1}$, Fernando Ferreira-Santos ${ }^{1}$, Fernando

3 Barbosa $^{1}$, João Marques-Teixeira ${ }^{1}$

$4{ }^{1}$ Laboratory of Neuropsychophysiology, Faculty of Psychology and Education Sciences,

5 University of Porto, Porto, Portugal

$6{ }^{2}$ Faculty of Medicine, University of Porto, Porto, Portugal

7 '3Language Research Laboratory, Institute of Molecular Medicine, Faculty of Medicine,

8 University of Lisbon, Lisbon, Portugal

10 Corresponding author:

11 Ana Gonçalves ${ }^{1}$

12

13 Email address: anasgoncalves@fpce.up.pt 


\section{Abstract}

25 Background. Emotion identification is a fundamental component of social cognition. Although

it is well established that a general cognitive decline occurs with advancing age, the effects of age on emotion identification is still unclear. A meta-analysis by Ruffman and colleagues (2008) explored this issue, but much research has been published since then, reporting inconsistent findings.

Methods. To examine age differences in the identification of facial expressions of emotion, we conducted a meta-analysis of 24 empirical studies $(N=1033$ older adults, $N=1135$ younger adults) published after 2008. Additionally, a meta-regression analysis was conducted to identify potential moderators.

Results. Results show that older adults less accurately identify facial expressions of anger, sadness, fear, surprise, and happiness compared to younger adults, strengthening the results obtained by Ruffman et al. (2008). However, meta-regression analyses indicate that effect sizes are moderated by sample characteristics and stimulus features. Importantly, the estimated effect size for the identification of fear and disgust increased for larger differences in the number of years of formal education between the two groups.

Discussion: We discuss several factors that might explain the age-related differences in emotion identification and suggest how brain changes may account for the observed pattern. Furthermore, moderator effects are interpreted and discussed. 


\section{Introduction}

Emotion identification is defined as the "ability to visually analyze the configuration of facial muscle orientations and movements in order to identify the emotion to which a particular expression is most similar" (Wilhelm et al., 2014, p. 3) and is a central component of nonverbal communication. The ability to accurately identify emotional expressions is essential for successful interpersonal functioning throughout the life span (Carstensen, Gross, \& Fung, 1997). The interpretation of the emotions that others are experiencing is important to avoid conflict and provide social support. Emotion identification ability is also fundamental to regulate behavior such as selectively attending and approaching to positively stimuli to elicit positive feelings and avoid negative ones (Gross, Richards, \& John, 2006). Importantly, presenting facial emotional stimuli is a valid and reliable approach in order to activate brain areas crucial for emotion processing (Fusar-Poli et al., 2009) and emotion identification tasks have been used in studies assessing emotional processing (Ebner \& Johnson, 2009; Gonçalves et al., 2018; Grady, Keightley, Hongwanishkul, Lee, \& Hasher, 2007; Mienaltowski, Corballis, Blanchard-Fields, Parks, \& Hilimire, 2011; Williams et al., 2006).

A substantial body of research proposes an age-related "positivity effect” (Mather \& Carstensen, 2005), defined as a tendency for older adults to attend to, and better memorize positive information relative to neutral and negative stimuli. According to the Socio-emotional Selectivity Theory (Carstensen, Isaacowitz, \& Charles, 1999), significant developmental changes occur in older adults' regulation and processing of affect. In this sense, the theory attributes the "positivity effect" to a motivational shift toward emotional regulation goals (i.e., achieving positive affect) as older adults begin to view their lifetime as limited (Carstensen et al., 1999). An alternative theoretical account of the age-related positivity effect, the dynamic integration 
theory, posits that greater cognitive demands required to process negative information lead older adults to automatically and preferentially process positive information (Labouvie-Vief, 2003).

A vast set of the literature shows emotion identification deficits in older adults (e.g. Isaacowitz et al., 2007; Sullivan and Ruffman, 2004). Furthermore, Ruffman and colleagues (2008) performed a meta-analysis to examine age differences in emotion identification across four modalities - faces, voices, bodies/contexts, and matching of faces to voices. Specifically in faces modality, Ruffman and colleagues (2008) found an age-related decline across all emotions, except for disgust. However, the mean effect sizes in the faces modality range from 0.07 to 0.34 across all emotions, reflecting inconsistencies among findings in the studies included. Following studies (García-Rodríguez et al., 2009; Orgeta, 2010; Suzuki \& Akiyama, 2013) also reported inconsistent findings, showing an age-related decline only in the identification of anger and fear (García-Rodriguez et al., 2009) and anger and sadness (Orgeta, 2010), that raise again questions about the effects of age on emotion identification.

Human aging is accompanied by the decline of various cognitive abilities (for a review, see Salthouse, 2009). For example, sustained attention and working memory decrease with age (Gazzaley et al., 2007; Park et al., 1996). Importantly, these cognitive abilities seem to be relevant to the performance in emotion identification tasks (Lambrecht, Kreifelts, \& Wildgruber, 2012). Furthermore, aging has been linked to a gradual reduction in visual acuity (Caban et al., 2005; Humes et al., 2009). Despite the well-known age-related decline in certain cognitive and sensory functions and its possible influence on emotion identification, the effects of age on emotion identification abilities remain unclear. 
91

92

93

94

95

96

97

98

Analyzing studies published after 2008, the present meta-analysis aims to clarify whether age-related difficulties in identifying facial emotional expressions exist, quantify the magnitude of age effects observed and identify potential moderators.

There are several factors known to influence the identification of facial expressions. Specifically, studies focusing on emotional facial expressions support the idea of a female advantage in emotion identification (Hall \& Matsumoto, 2004; Montagne et al., 2005; Williams et al., 2009). Furthermore, participants with no college education $\left(M_{\text {age }}=35.5, S D=13.1\right.$, range =19-69 years) were more likely to select the correct label for anger and sadness, than were those with a college degree $\left(M_{\text {age }}=33.9, S D=11.0\right.$, range $=19-64$ years $)$. For fear and disgust, the opposite pattern was reported (Trauffer et al., 2013). Besides participants characteristics, stimulus features need to be considered when analyzing different studies of emotion perception. For instance, color has been reported to improve the perception of general emotional clues (Silver \& Bilker, 2015). Additionally, dynamic stimuli can be more accurately recognized than the static ones as shown by behavioral studies (Ambadar, Schooler \& Cohn, 2005). Considering that most real-word emotion recognition involves motion of the perceiver and the target rather than looking at pictures, using dynamic stimuli in research makes sense (Isaacowitz \& Stanley, 2011). Another element that may contribute to the differential interpretation of static and dynamic facial expressions is motivation, particularly in older adults, since a static photo may create a perception of an overly artificial task, as well as very different from daily life, so that older adults may not engage sufficiently to perform well (Isaacowitz \& Stanley, 2011). Given these evidences, the variables sex, level of education of participants, and stimulus features (virtual vs natural, color vs black and white, static vs dynamic) were tested as moderators of any age effects observed. We expected to find larger effects for larger differences in the mean years 
114 of education between the groups to be compared, as well as for higher percentage of female

115 participants and dynamic colored pictures of faces. With the present study, we will clarify how

116 emotion identification of facial expressions changes along aging and identify potential

117 moderators.

118

119 Materials \& Methods

120 Literature search

121 A computer-based search of the PubMed, Web of Knowledge, and EBSCOhost

122 (including the Academic Search Complete, PsycARTICLES, Psychology and Behavioral

123 Sciences databases) was conducted in October 2017 by two researchers (ARG, CF). The search

124 expression was "(aging OR ageing OR "older adults" OR elderly) AND ("emotion recognition*”

125 OR “emotional processing" OR "emotion identification")". The search was limited to titles and

126 abstracts, published in English in the last nine years. In PubMed the filter "Humans" was also

127 used. A total of 1580 non-duplicated articles were found. Additionally, the references of the

128 included articles were searched manually to identify other relevant studies $(n=20)$.

\section{Selection criteria}

130 Studies assessing emotion identification in healthy younger $(20 \leq$ mean age $\leq 35)$ and older

131 adults (mean age $\geq 55$ years old) were included (criterion 1). Also, only studies that allowed

132 effect size data (i.e., sample sizes, means, and standard deviations) to be directly recorded,

133 calculated, or measured (i.e., from a graph) were included. Authors were contacted if effect sizes

134 could not be obtained from the published data. Ten studies that did not present descriptive

135 statistics and the information requested was not provided, were excluded (criterion 2). Studies 
136 that did not guarantee the neurological and psychological health of the participants, or had

137 missing details about the participants' inclusion criteria, were excluded ( $n=13$; criterion 3$)$.

After screening for relevant studies $(n=1600)$, considering the title and abstract, two

139

140

141

142 researchers (ARG, $\mathrm{CF})$ read the full-text of the studies that were retained $(n=85)$ and,

independently, decided their eligibility for further analysis. Disagreements were resolved by consensus. The inter-rater agreement Cohen's kappa was used to compare agreement between the researchers, revealing an almost perfect agreement $(k=.95)$.

Detailed information on the study selection process is described in the PRISMA Flow

\section{Recorded variables and data collection}

The data of each paper were added to an extraction sheet, developed for this metaanalysis and refined when necessary.

When present, the following variables were extracted from each paper: (a) characteristics of the sample (sample groups, sample size, number of female participants, age, years of education); (b) emotion identification tasks and conditions; (c) descriptive statistics of participants' performance; (d) significant statistical differences between younger and older adults' performance.

\section{Statistical analysis}

The Standard Mean Difference (SMD), based on Hedges' adjusted $g$ formulation, was used to assess the association between the two variables of interest, i.e. how much age-groups' performance differ on the emotion identification task. The $S M D$ was pooled across studies to derive an estimate of the mean (i.e., effect size based on Hedges' $g$ ), with each effect weighted for precision to correct for sampling error. To do so, a random-effects model was adopted. 

and sample characteristics of the studies included in the meta-analysis are detailed in Table 1.

161

162

163

164 165

Publication bias was assessed by visual inspection of the funnel plot. Egger's tests were used to estimate the severity of publication bias, with $p<.05$ considered statistically significant.

For each emotional expression, the unrestricted maximum likelihood random-effects

meta-regression of the effect size was performed with sex (\% female), differences in the level of education between older and younger adults, and stimulus features (virtual vs natural, color vs black and white, static vs dynamic) as moderators to determine whether these covariates influenced the effect size.

Statistical analyses were performed using Cochrane Collaboration Review Manager 5.3 (The Nordic Cochrane Centre, The Cochrane Collaboration, 2014) and SPSS version 22.0 (IBM Corp, 2013) software.

\section{Results}

The negative overall effect size for age-group across all emotions $(M=-1.80)$ showed that facial expressions were less accurately identified by older adults (Table 2). For each effect size, a negative value indicates that older adults have performed worse than younger adults, whereas a positive value indicates the reverse. When analyzing data by emotion, the combined effect sizes showed that facial expressions of anger, sadness, fear, surprise, and happiness were less accurately identified by older adults (Table 2). Regarding the identification of facial expressions of disgust, no significant differences were found between older and younger adults (Table 2). 
182

contributing to each of the estimates differ substantively. Effect sizes for individual studies are depicted in Table 3.

Egger's regression tests showed no significant funnel plot asymmetry across emotional expressions, indicating the inexistence of publication bias.

The meta-regression analyses showed a significant association between participants' performance by age-group and both sex and level of education as moderators on fear and disgust identification (Table 4). Specifically, differences in level of education are associated with effect sizes on the identification of fear and disgust expressions, with larger effects observed for larger differences in education. Regarding the moderator sex, larger effects are observed for higher percentages of female participants on the identification of fear and the opposite pattern (i.e., larger effects are observed for smaller percentages of female participants) is observed on the identification of disgust expression. A significant association was also found between stimulus features (virtual vs natural, color vs black and white, static vs dynamic) as moderator and performance by age-group on disgust identification. Concerning fear identification the association was marginally significant (Table 4). Whereas larger effects are observed for grayscale pictures of faces on the identification of disgust, larger effects are observed for virtual faces on the identification of fear.

\section{Discussion}

The present study aimed to identify potential age-related differences in identifying emotions in facial expressions and quantify the magnitude of the observed age effects. Using a meta-analytic approach with a random-effect model, our results showed that older adults 
204 identified facial expressions of anger, sadness, fear, surprise, and happiness less accurately than 205 younger adults. In contrast, identification of disgust appears to be preserved with age, as older

206

207

208

209

210

211

212

213

214

215

216

217

218

220

221

222

223

224

225

226

and younger adults' performance was similar in this case. The present results support those reported in a prior meta-analysis by Ruffman et al. (2008).

Taken together, our results are consistent with a general emotion identification decline associated with aging. Thus, this meta-analysis does not support a positivity bias in the identification of facial expressions of emotion, as impairments in this ability seem to extend to positive facial expressions, nor previous findings suggesting that aging is associated with a reduction in the negativity effect, rather than a positivity effect (Comblain et al., 2005; Denburg et al., 2003; Knight, Maines, \& Robinson, 2002; Mather et al., 2004). Age-related positivity effects were found primarily in attention to, and recall and recognition memory for emotional images which could have implications for emotion identification (Isaacowitz \& Stanley, 2011). Therefore, several studies aimed to investigate whether age differences in emotion identification performance could also reflect positivity effects (e.g. Williams et al., 2006). Importantly, many tasks assessing identification accuracy for positive emotions are constrained by ceiling effects (due to the relative low difficulty of the task); however, in the present data, the typical ceiling effects in younger adults' happiness recognition (e.g. Williams et al., 2006) seem to be absent. Furthermore, our meta-regression results showed a significant association between sample characteristics, namely the proportion of female participants and the level of education, and participants' performance by age-group on the identification of fear and disgust. Stimulus features were also found to be significantly associated with participant's performance by agegroup on disgust identification. Concerning fear identification, the association was marginally significant. Regarding the level of education, the effect size increases for larger differences in the 
227 mean years of education between the two groups. This result is consistent with the pattern

228 reported by Trauffer and colleagues (2013) in which participants with college education were

229 more likely to select the correct label for fear and disgust, than were those with no college

230 degree. According to the authors (Trauffer et al., 2013), the number of correct and incorrect

231 responses is partially influenced by the tendency to use certain labels. For instance, sadness and

232 ager have a broader meaning for preschoolers than for university undergraduates which matches

233 with the more frequent use of these words by participants with no college education, compared to

234 the ones with a college education (Trauffer et al., 2013). With respect to the moderator sex, the

235 pattern of effects observed suggests that female participants had better performance than male

236 participants when identifying fear expression and worst performance when identifying disgust.

237 For the identification of fear, the result is consistent with the idea of a female advantage in

238 overall emotion identification supported by studies focusing on emotional facial expressions

239 (Hall \& Matsumoto, 2004; Montagne et al., 2005; Williams et al., 2009). For the identification of

240 disgust, the result may be explained by the higher value of within-group heterogeneity found in

241 the analysis of disgust expression $\left(I_{\text {disgust }}^{2}=.880\right.$ vs. $\left.I_{\text {fear }}^{2}=.053\right)$. Contrary to what was expected,

242 the meta-regression results of stimulus features suggest that disgust was better identified on

243 grayscale pictures and fear was better identified on virtual faces. However, it should be noted

244 that the report of color to improve the perception of emotional clues (Silver \& Bilker, 2015)

245 refers to general emotional clues and not to one specific emotion. The better identification of fear

246 on virtual faces may be explained by less variability in expressive features, compared to natural

247 faces, which means by containing less noise (Dyck et al., 2008). Nevertheless, a note of caution

248 should be added here. Results of regression-based methods may not be robust in the current

249 meta-analysis, as such methods are more accurate with a larger number of studies. 

adults, present evidence that brain changes might be responsible for alterations in emotion identification performance (Brassen, Gamer, \& Büchel et al., 2011; Delgado et al., 2008; Ge et al., 2014; Murty et al., 2009; Urry et al., 2009). In particular, the prefrontal cortex and amygdala were found to be key players in the neural mechanisms underlying emotional regulation (Delgado et al., 2008; Murty et al., 2009). Mather and colleagues (2004) reported reduced amygdala activation for pictures of negative valence during their encoding in older adults. The authors suggested that the on-line reductions in response to negative pictures should cause disproportionately reduced subsequent memory for these negative stimuli. This pattern of amygdala activation was also found by Keightley and colleagues (2007). Our results regarding the identification of negative expressions, except for the identification of disgust, are consistent with the abovementioned evidence. Besides a general reduction of the amygdala response, according to Ruffman et al. (2008), the increased difficulty of older adults to recognize facial expressions of anger may be related to a functional decline in the orbitofrontal cortex, sadness to a decline in the cingulate cortex and amygdala, and fear to a decline in the amygdala.

Nevertheless, the identification of neural circuits rather than specific brain regions might be more successful when trying to explain the differences found between younger and older adults' performance (Almeida et al., 2016; Barrett \& Wager, 2006; Clark-Polner, Johnson, \& Barrett, 2016), including the identification of positive expressions. Impairments in cognitive and sensory functions might also explain the changes in emotion identification across the lifespan. Aging is often accompanied by a decline in cognitive abilities (for review, see Salthouse, 2009), as well as by losses in visual and auditory acuity

272 (Caban et al., 2005; Humes et al., 2009), which could hinder higher-level processes such as 
273 language and perception (Sullivan \& Ruffman, 2004). However, these sensory features have

274 been reported to be poor predictors of the decline in visual or auditory emotional identification

275 that occurs with aging (e.g., Lima et al., 2014; Ryan, Murray, \& Ruffman, 2010). We could not

276 examine these putative moderators due to a lack of consistent selection of cognitive ability

277 measures and its reporting across studies. Future studies incorporating common measures of

278 cognitive ability would allow addressing this issue.

279

As a final note, we highlight the ambiguity of emotion identification and emotion

280

281

282

283

284

285

286

287

288

289

290

291

292

293

\section{Conclusions \\ Conclusions}

recognition concepts in the literature. Some studies used both terms interchangeably (e.g.,

Circelli, Clark, \& Cronin-Golomb, 2013; Silver \& Bilker, 2015), while others distinguished the terms and used specific tasks to assess emotion identification and emotion recognition separately (Benito et al., 2013; Mathersul et al., 2009; Wilhelm et al., 2014). It is essential to use these concepts uniformly in future studies. In this meta-analysis, we applied the term emotion identification as the "ability to visually analyze the configuration of facial muscle orientations and movements in order to identify the emotion to which a particular expression is most similar" (Wilhelm et al., 2014). We assume that the term emotion recognition emphasizes a focus on memory for facial expressions of emotion, i.e. the "ability to correctly encode, store, and retrieve information regarding emotional expressions from memory systems" (Wilhelm et al., 2014). The ambiguity in the use of these terms may lead to misunderstandings during the phase of literature search and in the interpretation of the published results. In this sense, future studies should pay more attention to this issue. 
295 In sum, the present meta-analysis shows evidence of less accuracy of older adults in 296 emotion identification, not supporting a positivity bias nor a reduction in the negativity effect.

297 Meta-regression analyses suggest that effect sizes are moderated by sample characteristics such

298 as sex, level of education, as well as stimulus features. Several factors might explain the age-

299 related differences in emotion identification, but future studies are needed to explore whether and

300 to what extent they are involved.

301

302 
303

304

305

306

307

308

309

310

311

312

313

314

315

316

317

318

319

320

321

322

323

324

325

\section{References}

Almeida PR, Ferreira-Santos F, Chaves, P. L, Paiva TO, Barbosa F, Marques-Teixeira J. 2016. Perceived arousal of facial expressions of emotion modulates the N170, regardless of emotional category: Time domain and time-frequency dynamics. International Journal of Psychophysiology 99: 48-56. DOI: 10.1016/j.ijpsycho.2015.11.017

Ambadar Z, Schooler JW, Cohn JF. 2005. Deciphering the enigmatic face: the importance of facial dynamics in interpreting subtle facial expressions. Psychological Science 16: 403410. DOI: $10.1111 / \mathrm{j} .0956-7976.2005 .01548 . x$

*Baena E, Allen PA, Kaut KP, Hall RJ. 2010. On age differences in prefrontal function: The importance of emotional/cognitive integration. Neuropsychologia, 48: 319-333. DOI: 10.1016/j.neuropsychologia.2009.09.021

Barrett LF, Wager TD. 2006. The structure of emotion: evidence from neuroimaging studies. Current Directions in Psychological Science 15: 79-83. DOI: 10.1111/j.09637214.2006.00411.x

Benito A, Lahera G, Herrera S, Muncharaz R, Benito G, Fernández-Liria A, Montes JM. 2013. Deficits in recognition, identification, and discrimination of facial emotions in patients with bipolar disorder. Revista Brasileira de Psiquiatria 35: 435-438. DOI:10.1590/15164446-2013-1086

Brassen S, Gamer M, Büchel C. 2011. Anterior cingulate activation is related to a positivity bias and emotional stability in successful aging. Biological Psychiatry 70: 131-137. DOI:10.1016/j.biopsych.2010.10.013

Caban AJ, Lee DJ, Gómez-Marín O, Lam BL, Zheng DD. 2005. Prevalence of concurrent hearing and visual impairment in US adults: the national health interview survey, 1997- 
Cacioppo JT, Berntson GG, Bechara A, Tranel D, Hawkley LC. 2011. Could an aging brain contribute to subjective well-being? The value added by a social neuroscience perspective. In: Todorov A, Fiske S, Prentice D, ed. Social Neuroscience: Toward Understanding the Underpinnings of the Social Mind. New York: Oxford University Press, p. 249.

*Campbell A, Murray JE, Atkinson L, Ruffman T. 2015. Face age and eye gaze influence older Sciences and Social Sciences 0: 1-4. DOI:10.1093/geronb/gbv114

Campbell A, Ruffman T, Murray JE, Glue P. 2014. Oxytocin improves emotion recognition for older males. Neurobiology of Aging 35: 2246-2248. DOI:

10.1016/j.neurobiolaging.2014.04.021

Carstensen LL, Gross JJ, Fung HH. 1997. The social context of emotional experience. Annual Review of Gerontology and Geriatrics 17: 325-352.

Carstensen LL, Isaacowitz DM, Charles ST. 1999. Taking time seriously: a theory of socioemotional selectivity. American Psychologist 54: 165-181. DOI:10.1037/0003066X.54.3.165

*Carvalho C, Páris M, Lemos M, Peixoto B. 2014. Assessment of facial emotions recognition in aging and dementia. The development of a new tool. Biomedicine \& Aging Pathology 4: 91-94. DOI: 10.1016/j.biomag.2014.01.003

*Chaby L, Luherne-du Boullay V, Chetouani M, Plaza M. 2015. Compensating for age limits through emotional crossmodal integration. Frontiers in Psychology 6: 691. DOI:10.3389/fpsyg.2015.00691 
349 Charles ST, Mather M, Carstensen LL. 2003. Aging and emotional memory: The forgettable

350 nature of negative images for older adults. Journal of Experimental Psychology: General 132: 310-324. DOI: 10.1037/0096-3445.132.2.310

352

353

354

355

356

357

358

359

360

361

362

363

364

365

366

367

368

369

370

371

*Circelli KS, Clark US, Cronin-Golomb A. 2013. Visual scanning patterns and executive function in relation to facial emotion recognition in aging. Neuropsychology, development, and cognition: Section B. Aging, neuropsychology and cognition 20: 148-173. DOI:10.1080/13825585.2012.675427

Clark-Polner E, Johnson TD, Barrett LF. 2016. Multivoxel Pattern Analysis Does Not Provide Evidence to Support the Existence of Basic Emotions. Cerebral Cortex, 1-5. DOI: 10.1093/cercor/bhw028

Comblain C, D'Argembeau A, Van der Linden M. 2005. Phenomenal characteristics of autobiographical memories for emotional and neutral events in older and younger adults. Experimental Aging Research 31: 173-189. DOI: 10.1080/03610730590915010

D’Argembeau A, Van der Linden M. 2004. Identity but not expression memory for unfamiliar faces is affected by ageing. Memory 12: 644-654. DOI: 10.1080/09658210344000198

Delgado MR, Nearing KI, Ledoux JE, Phelps EA. 2008. Neural circuitry underlying the regulation of conditioned fear and its relation to extinction. Neuron 59: 829-838. DOI:10.1016/j.neuron.2008.06.029

Denburg NL, Buchanan TW, Tranel D, Adolphs R. 2003. Evidence for preserved emotional memory in normal older persons. Emotion 3: 239-253. DOI:10.1037/1528-3542.3.3.239

Demenescu LR, Mathiak KA, Mathiak K. 2014. Age- and Gender-Related Variations of Emotion Recognition in Pseudowords and Faces. Experimental Aging Research 40: 187-207. DOI: $10.1080 / 0361073 X .2014 .882210$ 
372 Dyck M, Winbeck M, Leiberg S, Chen Y, Gur RC, Mathiak K (2008) Recognition Profile of

373 Emotions in Natural and Virtual Faces. PLoS ONE 3(11): e3628.

374 http://doi.org/10.1371/journal.pone.0003628

375 Ebner NC, He Y, Johnson MK. 2011. Age and Emotion Affect How We Look at a Face: Visual 376 Scan Patterns Differ for Own-Age versus Other-Age Emotional Faces. Cognition and Emotion 25: 983-997. DOI:10.1080/02699931.2010.540817

378

379

380

381

382

383

384

385

386

387

388

389

390

391

392

Ebner NC, Johnson MK. 2009. Young and older emotional faces: Are there age group differences in expression identification and memory? Emotion 9: 329-339. DOI:10.1037/a0015179

*Ebner NC, Johnson MK, Fischer H. (2012). Neural mechanisms of reading facial emotions in young and older adults. Frontiers in Psychology 3: 223. DOI: 10.3389/fpsyg.2012.00223

*Ebner NC, Riediger M, Lindenberger U. 2010. FACES - a database of facial expressions in young, middle-aged, and older women and men: development and validation. Behavior Research Methods 42: 351-362. DOI: 10.3758/BRM.42.1.351

Fusar-Poli P, Placentino A, Carletti F, Landi P, Allen P, Surguladze S, ... Politi P. 2009. Functional atlas of emotional faces processing: a voxel-based meta-analysis of 105 functional magnetic resonance imaging studies. Journal of Psychiatry and Neuroscience 34: $418-432$.

Finkel D, Reynolds CA, McArdle JJ, Pedersen NL. 2007. Cohort differences in trajectories of cognitive aging. The Journals of Gerontology: Series B. Psychological Sciences and Social Sciences 62: 286-294. 
393 García-Rodríguez B, Ellgring HB, Fusaria A, Frank A. 2009. The role of interference in

394 identification of emotional facial expressions in normal ageing and dementia. European Journal of Cognitive Psychology 21: 428-444. DOI:10.1080/09541440802475793

396

397

398

399

400

401

402

403

404

405

406

407

408

409

410

411

412

413

414

García-Rodríguez B, Fusari A, Fernández-Guinea S, Frank A, Molina JA., Ellgring H. 2011. Decline of executive processes affects identification of emotional facial expression in aging. Current Aging Science 4 70-5. DOI: 10.2174/1874609811104010070

*García-Rodríguez B, Fusari A, Rodríguez B, Hernández JMZ, Ellgring H. 2009. Differential patterns of implicit emotional processing in Alzheimer's disease and healthy aging. Journal of Alzheimer's Disease 18: 541-551. DOI:10.3233/JAD-2009-1161

Gazzaley A, Sheridan MA, Cooney JW, D’Esposito M. 2007. Age-related deficits in component processes of working memory. Neuropsychology 21: 532-539. DOI:10.1037/08944105.21.5.532

Ge R, Fu Y, Wang D, Yao L, Long Z. 2014. Age-related alterations of brain network underlying the retrieval of emotional autobiographical memories: an fMRI study using independent component analysis. Frontiers in Human Neuroscience 8: 1-17.

DOI:10.3389/fnhum.2014.00629

Gerstorf D, Ram N, Hoppmann C, Willis SL, Schaie KW. 2011. Cohort differences in cognitive aging and terminal decline in the Seattle Longitudinal Study. Developmental Psychology 47: 1026-41.DOI: 10.1037/a0023426

Gonçalves AR, Fernandes C, Pasion R, Ferreira-Santos F, Barbosa F, Marques-Teixeira J. 2018. Emotion identification and aging: behavioral and neural age-related changes. Clinical Neurophysiology 129: 1020-1029. DOI: 10.1016/j.clinph.2018.02.128 
415 Grady CL, Keightley M, Hongwanishkul D, Lee W, Hasher L. 2007. The effect of age on 416 memory for emotional faces. Neuropsychology 21: 371-380. DOI:10.1037/08944105.21.3.371

418 Gross JJ, Richards JM, John OP. 2006. Emotion regulation in everyday life. In: Snyder DK, 419 Simpson JA, Hughes JN, ed. Emotion regulation in couples and families: Pathways to dysfunction and health. Washington, DC: American Psychological Association, 13-35.

421 Gunning-Dixon F, Gur RC, Perkins AC, Schroeder L, Turner T, Turetsky BI, . . Gur RE. 2003.

422

423

424

425

426

427

428

429

430

431

432

433

434

435

436 Age-related differences in brain activation during emotional face processing. Neurobiology of Aging 24: 285-295. DOI: 10.1016/S0197-4580(02)00099-4

*Halberstadt J, Ruffman T, Murray J, Taumoepeau M, Ryan M. 2011. Emotion perception explains age-related differences in the perception of social gaffes. Psychology and Aging 26: 133-136. DOI: $10.1037 / \mathrm{a} 0021366$

Hall JA, Matsumoto D. 2004. Gender differences in judgments of multiple emotions from facial expressions. Emotion 4: 201-206. DOI:10.1037/1528-3542.4.2.201

Hayes AM, Yasinski C. 2015. Pattern destabilization and emotional processing in cognitive therapy for personality disorders. Frontiers in Psychology. 6:107. DOI:10.3389/fpsyg.2015.00107.

Humes LE, Busey TA, Craig, JC, Kewley-Port D. 2009. The effects of age on sensory thresholds and temporal gap detection in hearing, vision, and touch. Attention, Perception, \& Psychophysics 71: 860-871. DOI:10.3758/APP.71.4.860

*Hunter EM, Phillips LH, Macpherson SE. 2010. Effects of age on cross-modal emotion perception. Psychology and Aging 25: 779-787. DOI: 10.1037/a0020528 
437 Iidaka T, Okada T, Murata T, Omori M, Kosaka H, Sadato N, Yonekura Y. 2002. Age-related

438 differences in the medial temporal lobe responses to emotional faces as revealed by fMRI.

439 Hippocampus 12: 352-362. DOI:10.1002/hipo.1113

440

441

442

443

444

445

446

447

448

449

450

451

452

453

454

455

456

457

Irani F, Brensinger CM, Richard J, Calkins ME, Moberg PJ, Bilker W, . . Gur RC. 2012.

Computerized neurocognitive test performance in schizophrenia: a lifespan analysis. American Journal of Geriatric Psychiatry 20: 41-52. DOI:

10.1097/JGP.0b013e3182051a7d

Isaacowitz DM, Stanley JT. 2011. Bringing an Ecological Perspective to the Study of Aging and Recognition of Emotional Facial Expressions: Past, Current, and Future Methods. Journal of Nonverbal Behavior 35: 261-278. DOI: 10.1007/s10919-011-0113-6

Isaacowitz DM, Löckenhoff CE, Lane RD, Wright R, Sechrest L, Riedel R, Costa PT. 2007. Age differences in recognition of emotion in lexical stimuli and facial expressions. Psychology and Aging 22: 147-159. DOI: 10.1037/0882-7974.22.1.147

Keightley ML, Chiew KS, Winocur G, Grady CL. 2007. Age-related differences in brain activity underlying identification of emotional expressions in faces. Social Cognitive and Affective Neuroscience 2: 292-302. DOI: 10.1093/scan/nsm024

Kensinger EA, Piguet O, Krendl AC, Corkin S. 2005. Memory for contextual details: Effects of emotion and aging. Psychology and Aging 20: 241-250. DOI: 10.1037/0882-7974.20.2.241

Knight BG, Maines ML, Robinson GS. 2002. The effects of sad mood on memory in older adults: A test of the mood congruence effect. Psychology and Aging 17: 653-661. DOI: 10.1037/0882-7974.17.4.653 
458 *Krendl AC, Ambady N. 2010. Older adults' decoding of emotions: role of dynamic rersus static $459 \quad$ cues and age-related cognitive decline. Psychology and Aging 25: 788-793. DOI:

460 $10.1037 / \mathrm{a} 0020607$

461

462

463

464

465

466

467

468

469

470

471

472

473

474

475

476

477

478

479

*Krendl AC, Ambady N, Rule NO. 2014. Does aging impair first impression accuracy? Differentiating emotion recognition from complex social inferences. Psychology and Aging 29: 482-490. DOI: $10.1037 / \mathrm{a} 0037146$

Kunzmann U, Kupperbusch CS, Levenson RW. 2005. Behavioral inhibition and amplification during emotional arousal: a comparison of two age groups. Psychology and Aging 20: 144158. DOI:10.1037/0882-7974.20.1.144

Labouvie-Vief G. 2003. Dynamic integration: affect, cognition, and the self in adulthood. Current Directions in Psychological Science 12: 201-206. DOI:10.1046/j.09637214.2003.01262.x

*Lambrecht L, Kreifelts B, Wildgruber D. 2012. Age-related decrease in recognition of emotional facial and prosodic expressions. Emotion 12: 529-539. DOI: 10.1037/a0026827

Leclerc CM, Kensinger EA. 2008. Age-related differences in medial pre-frontal in response to emotional images. Cognitive, Affective, \& Behavioral Neuroscience 8: 153-164. DOI:10.3758/CABN.8.2.153

Leclerc CM, Kensinger EA. 2011. Neural processing of emotional pictures and words: a comparison of young and older adults. Developmental Neuropsychology 36: 519-538. DOI:10.1080/87565641.2010.549864

Leigland LA, Schulz LE, Janowsky JS. 2004. Age related changes in emotional memory. Neurobiology of Aging 25: 1117-1124. DOI: 10.1016/j.neurobiolaging.2003.10.015 
480 Lima CF, Alves T, Scott SK, Castro SL. 2014. In the ear of the beholder: how age shapes

481 emotion processing in nonverbal vocalizations. Emotion 14: 145-160.

482 DOI:10.1037/a0034287

483

484

485

486

487

488

489

490

491

492

493

494

495

496

497

498

499

500

501

Mather M, Canli T, English T, Whitfield S, Wais P, Ochsner K, . . Carstensen L L. 2004. Amygdala responses to emotionally valenced stimuli in older and younger adults. Psychological Science 15: 259-263. DOI: 10.1111/j.0956-7976.2004.00662.x

Mather M, Carstensen LL. 2003. Aging and attentional biases for emotional faces. Psychological Science 14: 409-415. DOI: 10.1111/1467-9280.01455

Mather M, Carstensen LL. 2005. Aging and motivated cognition: the positivity effect in attention and memory. Trends in Cognitive Sciences 9: 496-502. DOI:10.1016/j.tics.2005.08.005

Mather M, Knight M. 2005. Goal-directed memory: The role of cognitive control in older adults' emotional memory. Psychology and Aging 20: 554-570. DOI:10.1037/0882-7974.20.4.554

Mathersul D, Palmer DM, Gur RC, Gur RE, Cooper N, Gordon E, Williams LM. 2009. Explicit identification and implicit recognition of facial emotions: II. Core domains and relationships with general cognition. Journal of Clinical and Experimental Neuropsychology 31: 278-291. DOI: 10.1080/13803390802043619

Mienaltowski A, Corballis PM, Blanchard-Fields F, Parks NA, Hilimire MR. 2011. Anger management: Age differences in emotional modulation of visual processing. Psychology and Aging 26: 224-231. DOI:10.1037/a0021032

Montagne B, Kessels RPC, Frigerio E, de Haan EHF, Perrett DI. 2005. Sex differences in the perception of affective facial expressions: Do men really lack emotional sensitivity? Cognitive Processing 6: 136-141. doi:10.1007/s10339-005-0050-6 
502

503

504

505

506

507

508

509

510

511

512

513

514

515

516

517

518

519

520

521

522

523

*Murphy NA, Isaacowitz, DM. 2010. Age effects and gaze patterns in recognising emotional expressions: An in-depth look at gaze measures and covariates. Cognition and Emotion 24: 436-452. DOI: 10.1080/02699930802664623

Murty VP, Sambataro F, Das S, Tan HY, Callicott JH, Goldberg TE, . . . Mattay VS. 2009. Agerelated alterations in simple declarative memory and the effect of negative stimulus valence. Journal of Cognitive Neuroscience 21: 1920-1933. DOI:10.1162/jocn.2009.21130

*Ngo N, Isaacowitz DM. 2015. Use of context in emotion perception: The role of top-down control, cue type, and perceiver's age. Emotion 15: 292-302. DOI: 10.1037/emo0000062

*Noh SR, Isaacowitz DM 2013. 'Emotional Faces in Context: Age Differences in Recognition Accuracy and Scanning Patterns'. Emotion 13: 238-249. DOI:10.1037/a0030234

*Orgeta V. 2010. Effects of age and task difficulty on recognition of facial affect. The Journals of Gerontology: Series B. Psychological Sciences and Social Sciences 65: 323-327. DOI:10.1093/geronb/gbq007

Ochsner KN, Gross JJ. 2005. The cognitive control of emotion. Trends in Cognitive Sciences 9: 242-249. DOI:10.1016/j.tics.2005.03.010

Park DC, Smith AD, Lautenschlager G, Earles JL, Frieske D, Zwahr M. 1996. Mediators of long-term memory performance across the life span. Psychology and Aging 11: 621-637. DOI:10.1037/0882-7974.11.4.621

Phillips LH, MacLean RDJ, Allen R. 2002. Age and the understanding of emotions: neuropsychological and sociocognitive perspectives. The Journals of Gerontology: Series $B$. Psychological Sciences and Social Sciences 57: 526-530. DOI: 10.1093/geronb/57.6.P526 
524 Ruffman T, Halberstadt J, Murray J. 2009. Recognition of facial, auditory, and bodily emotions

525 in older adults. The Journals of Gerontology: Series B. Psychological Sciences and Social

$526 \quad$ Sciences 64: 696-703. DOI:10.1093/geronb/gbp072

527 Ruffman T, Henry JD, Livingstone V, Phillips LH. 2008. A meta-analytic review of emotion 528 recognition and aging: implications for neuropsychological models of aging. Neuroscience 529 \& Biobehavioral Reviews 32: 863-881. DOI:10.1016/j.neubiorev.2008.01.001

530 Ruffman T, Murray J, Halberstadt J, Taumoepeau M. 2010. Verbosity and emotion recognition $531 \quad$ in older adults. Psychology and Aging 25: 492-7. DOI: 10.1037/a0018247

532 Ryan M, Murray J, Ruffman T. 2010. Aging and the perception of emotion: processing vocal 533 expressions alone and with faces. Experimental Aging Research, 36, 1-22.

$534 \quad$ DOI: $10.1080 / 03610730903418372$

535 Salthouse TA. 2009. When does age-related cognitive decline begin? Neurobiology of Aging, 30, 536 507-514. DOI: 10.1016/j.neurobiolaging.2008.09.023.

537 *Sarabia-Cobo CM, Navas MJ, Ellgring H, García-Rodríguez B. 2015. Skilful communication:

538 Emotional facial expressions recognition in very old adults. International Journal of

$539 \quad$ Nursing Studies 54: 104-111. DOI: 10.1016/j.ijnurstu.2015.08.005

540 Schaffer SG, Wisniewski A, Dahdah M, Froming KB. 2009. The comprehensive affect testing 541 system-abbreviated: effects of age on performance. Archives of Clinical Neuropsychology 542 24: 89-104. DOI: 10.1093/arclin/acp012

543 Silver H, Bilker WB. 2014. Social cognition in schizophrenia and healthy aging: differences and 544 similarities. Schizophrenia Research 160: 157-62. DOI: 10.1016/j.schres.2014.11.002. 
$545 *$ Silver H, Bilker WB. 2015. Colour influences perception of facial emotions but this effect is

546 impaired in healthy ageing and schizophrenia. Cognitive Neuropsychiatry 20: 438-455.

547 DOI: $10.1080 / 13546805.2015 .1080157$

548 St Jacques PL, Bessette-Symons B, Cabeza R. 2009. Functional neuroimaging studies of aging

549 and emotion: fronto-amygdalar differences during emotional perception and episodic

550 memory. Journal of the International Neuropsychological Society 15: 819-825.

$551 \quad$ DOI: $10.1017 / \mathrm{S} 1355617709990439$

552 *Sullivan S, Campbell A, Hutton SB, Ruffman T. 2015. What's good for the goose is not good

553 for the gander: Age and gender differences in scanning emotion faces. The Journals of

554 Gerontology: Series B. Psychological Sciences and Social Sciences 0: 1-6.

555 DOI:10.1093/geronb/gbv033

556 Sullivan S, Ruffman T. 2004. Emotion recognition deficits in the elderly. International Journal

557 of Neuroscience 114: 403-442. DOI:10.1080/00207450490270901

558 Sullivan S, Ruffman T, Hutton S. 2007. Age differences in emotion recognition skills and the

559 visual scanning of emotion faces. The Journals of Gerontology: Series B. Psychological

$560 \quad$ Sciences and Social Sciences 62: 53-60.

561 *Suzuki T, Akiyama H. 2013. Cognitive aging explains age-related differences in face-based

562 recognition of basic emotions except for anger and disgust. Aging, Neuropsychology, and

563 Cognition 20: 253-270. DOI: 10.1080/13825585.2012.692761

564 *Svärd J, Wiens S, Fischer H. 2012. Superior recognition performance for happy masked and

565 unmasked faces in both younger and older adults. Frontiers in Psychology 3: 1-11. DOI:

$566 \quad 10.3389 /$ fpsyg. 2012.00520 
567 Trauffer N, Widen SC, Russell JA. 2013. Education and the attribution of emotion to facial

$568 \quad$ expressions. Psychological Topics 22: 237-247.

569 Tsai JL, Levenson RW, Carstensen LL. 2000. Autonomic, subjective, and expressive responses

570 to emotional films in older and younger Chinese Americans and European Americans.

$571 \quad$ Psychology and Aging 15: 684-693. DOI:10.1037/0882-7974.15.4.684

572 Urry HL, van Reekum CM, Johnstone T, Davidson RJ. 2009. Individual differences in some (but 573 not all) medial prefrontal regions reflect cognitive demand while regulating unpleasant 574 emotion. Neuroimage 47: 852-863. DOI:10.1016/j.neuroimage.2009.05.069

575 Wilhelm O, Hildebrandt A, Manske K, Schacht A, Sommer W. 2014. Test battery for measuring 576 the perception and recognition of facial expressions of emotion. Frontiers in Psychology 5:

577 1-23. DOI: 10.3389/fpsyg.2014.00404

578 Wong B, Cronin-Golomb A, Neargarder S. 2005. Patterns of visual scanning as predictors of 579 emotion identification in normal aging. Neuropsychology 19: 739-749. DOI: 10.1037/0894-4105.19.6.739

581

582

583

584

585

586

587

588

589

Williams LM, Brown KJ, Palmer D, Liddell BJ, Kemp AH, Olivieri G, . . Gordon, E. (2006). The mellow years?: Neural basis of improving emotional stability over age. Journal of Neuroscience 26: 6422-6430. DOI: 10.1523/JNEUROSCI.0022-06.2006

Williams LM, Mathersul D, Palmer DM, Gur RC, Gur RE, Gordon E. 2009. Explicit identification and implicit recognition of facial emotions: I. Age effects in males and females across 10 decades. Journal of Clinical and Experimental Neuropsychology 31: 257-77. DOI: $10.1080 / 13803390802255635$

Zelinski EM, Kennison RF. 2007. Not your parents' test scores: cohort reduces psychometric aging effects. Psychology and Aging 22: 546-557. DOI: 10.1037/0882-7974.22.3.546 
591

592

593 


\section{Figure 1 (on next page)}

PRISMA flow diagram. 

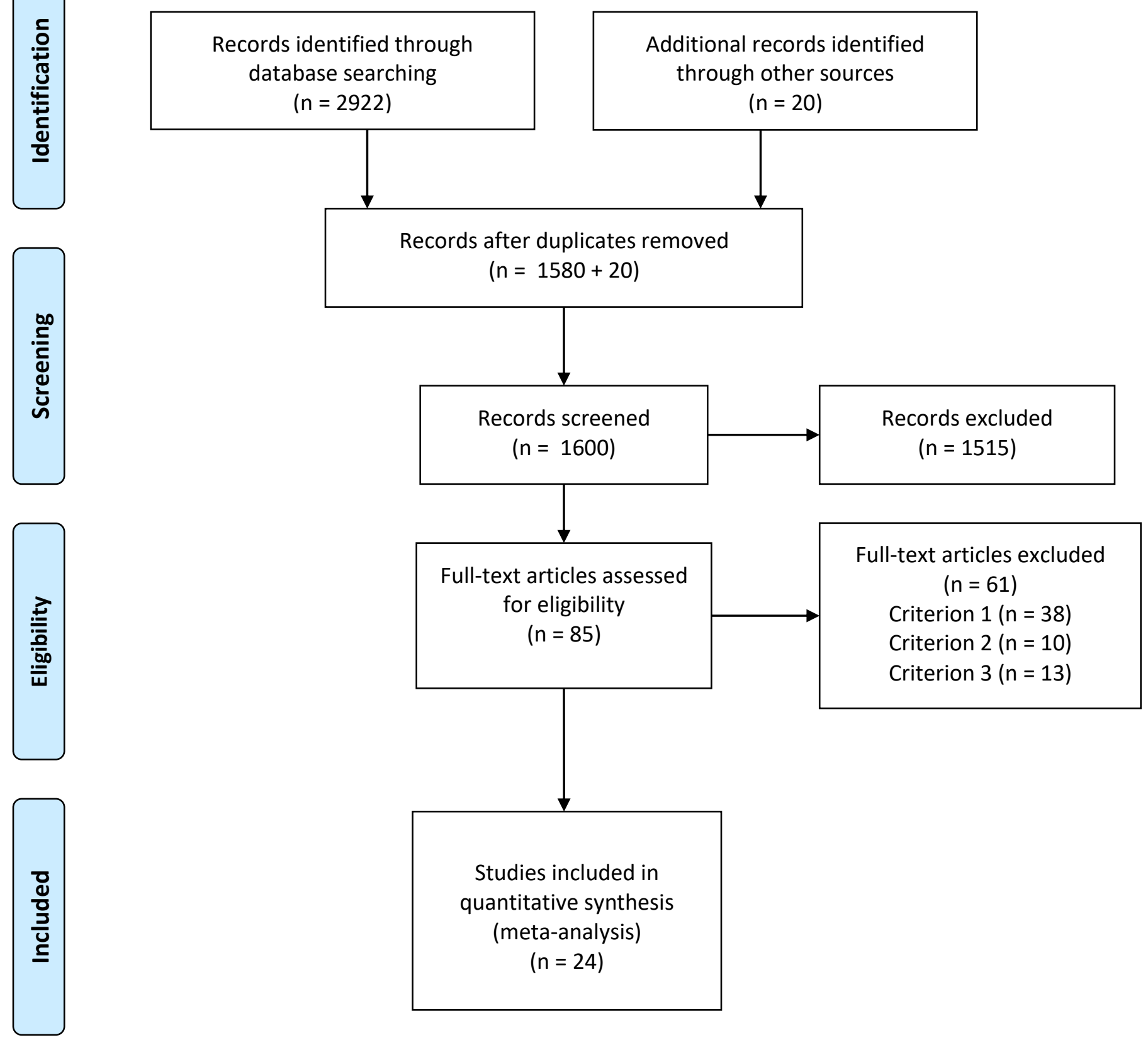


\section{Table $\mathbf{1}$ (on next page)}

Methodological and Sample Characteristics of Studies Included in the Meta-Analysis 




28 Note. Condition: $\mathrm{YF}=$ young faces; EIP = emotional intensity pronounced. Paradigm: $\mathrm{EIT}=$ emotion identification

29 task; DANVA2 = DANVA2 adults face task; DANVA2 M = DANVA2 modified task; URT = unmasked

30 recognition task; EEI = explicit emotion identification. Stimuli: $\mathrm{VHF}=$ virtual human faces; FACC $=$ colour photos

31 of human faces; GFAC = grey scale photos of human faces; VFAC = video sequences of human faces. Sample size:

$32 \mathrm{~F}=$ number of females 
Table 2 (on next page)

Age effects for recognition of different emotions 
2

\begin{tabular}{ccccc}
\hline & $M$ & $K$ & $N$ & $I^{2}$ \\
\hline Anger & $-0.61 * * *$ & 21 & 1785 & $.76^{* * *}$ \\
Sadness & $-0.43 * * *$ & 18 & 1661 & $.64 * * *$ \\
Fear & $-0.62 * * *$ & 18 & 1606 & $.53 * *$ \\
Disgust & -0.04 & 16 & 1480 & $.88^{* * *}$ \\
Surprise & $-0.45^{* * *}$ & 9 & 621 & $.90^{* * *}$ \\
Happiness & $-0.19^{*}$ & 22 & 1832 & $.70^{* * *}$ \\
Overall & $-1.80^{* * *}$ & 24 & 1978 & $.98^{* * *}$ \\
\hline
\end{tabular}

3 Note. $M=$ mean effect size. $K=$ number of independent studies contributing towards each respective mean effect

4 size. A negative effect size denotes that older adults are worse than younger adults; a positive effect size indicates

5 the reverse. $N=$ number of participants. $I^{2}$ quantifies within-group heterogeneity. Significances are marked by $* p<$ $6.05, * * p<.01$, and $* * * p<.001$. 


\section{Table 3 (on next page)}

Effect Size Data for Individual Studies Included in the Meta-Analysis 
2

\begin{tabular}{|c|c|c|c|}
\hline Study & Sample size & Weight (\%) & Effect size $[95 \% \mathrm{CI}]$ \\
\hline \multicolumn{4}{|l|}{ Anger } \\
\hline Campbell et al., 2015 & 64 & 4.9 & $-0.74[-1.25,-0.23]$ \\
\hline Carvalho et al., 2014 & 29 & 3.3 & $-1.32[-2.14,-0.49]$ \\
\hline Chaby et al., 2015 & 62 & 4.8 & $-0.87[-1.40,-0.35]$ \\
\hline Circelli et al., 2013 & 32 & 3.9 & $0.30[-0.40,1.00]$ \\
\hline Ebner et al., 2010 & 103 & 5.4 & $-0.87[-1.27,-0.47]$ \\
\hline Ebner et al., 2012 & 60 & 4.9 & $0.15[-0.36,0.65]$ \\
\hline García-Rodríguez, Fusari et al., 2009 & 32 & 2.6 & $-2.84[-3.86,-1.83]$ \\
\hline Halberstadt et al., 2011 & 121 & 5.7 & $-0.51[-0.88,-0.15]$ \\
\hline Hunter et al., 2010/ Study 1 & 50 & 4.4 & $-1.00[-1.59,-0.41]$ \\
\hline Krendl et al., 2010/Study 1 & 78 & 5.2 & $-0.63[-1.09,-0.17]$ \\
\hline Krendl et al., 2014 & 62 & 4.8 & $-0.93[-1.45,-0.40]$ \\
\hline Lambrecht et al., 2012 & 33 & 3.6 & $-1.31[-2.07,-0.55]$ \\
\hline Murphy and Isaacowitz, 2010 & 64 & 4.7 & $-0.98[-1.52,-0.44]$ \\
\hline Ngo and Isaacowitz, 2015/ Study 1 & 61 & 4.8 & $-0.80[-1.32,-0.27]$ \\
\hline Noh and Isaacowitz, 2015 & 84 & 5.3 & $-0.41[-0.85,0.02]$ \\
\hline Orgeta, 2010 & 80 & 5.3 & $0.00[-0.44,0.44]$ \\
\hline Sarabia-Cobo et al., 2015 & 87 & 5.3 & $-0.51[-0.95,-0.08]$ \\
\hline Sullivan et al., 2015 & 118 & 5.7 & $-0.28[-0.64,0.08]$ \\
\hline Suzuki and Akiyama, 2013 & 72 & 5.0 & $-0.72[-1.20,-0.24]$ \\
\hline Williams et al., 2009 & 452 & 6.4 & $-0.64[-0.83,-0.44]$ \\
\hline Ziaei et al., 2017 & 40 & 4.1 & $1.06[0.39,1.73]$ \\
\hline \multicolumn{4}{|l|}{ Sadness } \\
\hline Baena et al., 2010 & 78 & 5.9 & $-0.09[-0.53,0.36]$ \\
\hline Campbell et al., 2015 & 64 & 5.4 & $-0.36[-0.85,0.14]$ \\
\hline Carvalho et al., 2014 & 29 & 3.5 & $0.21[-0.53,0.95]$ \\
\hline Chaby et al., 2015 & 62 & 5.1 & $-1.02[-1.55,-0.49]$ \\
\hline Circelli et al., 2013 & 32 & 3.8 & $-0.34[-1.04,0.36]$ \\
\hline Ebner et al., 2010 & 103 & 6.5 & $-0.37[-0.76,0.02]$ \\
\hline García-Rodríguez, Fusari et al., 2009 & 32 & 3.7 & $0.65[-0.06,1.37]$ \\
\hline Halberstadt et al., 2011 & 121 & 6.8 & $-0.29[-0.65,0.07]$ \\
\hline Hunter et al., 2010/ Study 1 & 50 & 4.6 & $-0.91[-1.50,-0.33]$ \\
\hline Krendl et al., 2010/Study 1 & 78 & 5.8 & $-0.48[-0.93,-0.03]$ \\
\hline Krendl et al., 2014 & 62 & 5.3 & $-0.57[-1.08,-0.06]$ \\
\hline Murphy and Isaacowitz, 2010 & 64 & 5.2 & $-0.61[-1.14,-0.09]$ \\
\hline Orgeta, 2010 & 80 & 5.5 & $-1.38[-1.87,-0.89]$ \\
\hline Sarabia-Cobo et al., 201 & 87 & 6.0 & $-0.47[-0.90,-0.04]$ \\
\hline Silver and Bilker, 2015 & 76 & 5.8 & $-0.56[-1.02,-0.10]$ \\
\hline Sullivan et al., 2015 & 118 & 6.8 & $-0.28[-0.64,0.08]$ \\
\hline Suzuki and Akiyama, 2013 & 72 & 5.7 & $-0.54[-1.01,-0.07]$ \\
\hline Williams et al., 2009 & 452 & 8.6 & $-0.13[-0.32,0.06]$ \\
\hline \multicolumn{4}{|l|}{ Fear } \\
\hline Campbell et al., 2015 & 64 & 5.5 & $-0.46[-0.96,0.04]$ \\
\hline Carvalho et al., 2014 & 29 & 3.3 & $-0.22[-0.96,0.52]$ \\
\hline Chaby et al., 2015 & 62 & 5.4 & $-0.36[-0.86,0.15]$ \\
\hline Circelli et al., 2013/ Study 1 & 32 & 3.6 & $-0.52[-1.23,0.18]$ \\
\hline Ebner et al., 2010 & 103 & 6.9 & $-0.50[-0.89,-0.11]$ \\
\hline García-Rodríguez, Fusari et al., 2009 & 32 & 2.7 & $-1.93[-2.79,-1.07]$ \\
\hline Halberstadt et al., 2011 & 121 & 7.4 & $-0.07[-0.43,0.28]$ \\
\hline
\end{tabular}




\begin{tabular}{|c|c|c|c|}
\hline Study & Sample size & Weight $(\%)$ & Effect size $[95 \% \mathrm{CI}]$ \\
\hline Hunter et al., 2010/ Study 1 & 50 & 4.7 & $-0.61[-1.18,-0.04]$ \\
\hline Krendl et al., 2010/Study 1 & 78 & 6.0 & $-0.60[-1.06,-0.14]$ \\
\hline Krendl et al., 2014 & 62 & 5.5 & $-0.10[-0.59,0.40]$ \\
\hline Murphy and Isaacowitz, 2010 & 64 & 4.8 & $-1.23[-1.79,-0.68]$ \\
\hline Ngo and Isaacowitz, 2015/ Study 1 & 61 & 5.2 & $-0.75[-1.27,-0.23]$ \\
\hline Orgeta, 2010 & 80 & 6.1 & $-0.52[-0.97,0.08]$ \\
\hline Sarabia-Cobo et al., 2015 & 87 & 6.0 & $-1.04[-1.50,-0.59]$ \\
\hline Sullivan et al., 2015 & 118 & 7.2 & $-0.65[-1.02,-0.28]$ \\
\hline Suzuki and Akiyama, 2013 & 72 & 5.6 & $-0.98[-1.48,-0.49]$ \\
\hline Svärd et al., 2012 & 39 & 4.0 & $-0.66[-1.31,-0.02]$ \\
\hline Williams et al., 2009 & 452 & 10.0 & $-0.64[-0.83,-0.44]$ \\
\hline \multicolumn{4}{|l|}{ Disgust } \\
\hline Campbell et al., 2015 & 64 & 6.4 & $-0.39[-0.88,0.11]$ \\
\hline Carvalho et al., 2014 & 29 & 6.0 & $-0.57[-1.33,0.18]$ \\
\hline Chaby et al., 2015 & 62 & 5.5 & $0.92[0.39,1.44]$ \\
\hline Circelli et al., 2013/ Study 1 & 32 & 6.1 & $0.31[-0.39,1.01]$ \\
\hline Ebner et al., 2010 & 103 & 6.5 & $-0.56[-0.95,-0.16]$ \\
\hline García-Rodríguez, Fusari et al., 2009 & 32 & 5.9 & $-0.38[-1.08,0.32]$ \\
\hline Halberstadt et al., 2011 & 121 & 6.5 & $0.72[0.36,1.09]$ \\
\hline Hunter et al., 2010/ Study 1 & 50 & 6.3 & $-0.11[-0.67,0.44]$ \\
\hline Lambrecht et al., 2012 & 33 & 6.0 & $-1.53[-2.31,-0.74]$ \\
\hline Ngo and Isaacowitz, 2015/ Study 1 & 61 & 6.1 & $-0.49[-1.00,0.02]$ \\
\hline Noh and Isaacowitz, 2015 & 84 & 6.3 & $0.31[-0.12,0.75]$ \\
\hline Orgeta, 2010 & 80 & 6.3 & $0.37[-0.08,0.81]$ \\
\hline Sarabia-Cobo et al., 2015 & 87 & 6.4 & $-1.21[-1.67,-0.74]$ \\
\hline Sullivan et al., 2015 & 118 & 6.5 & $0.30[-0.06,0.66]$ \\
\hline Suzuki and Akiyama, 2013 & 72 & 6.4 & $0.58[0.11,1.05]$ \\
\hline Williams et al., 2009 & 452 & 6.6 & $0.62[0.43,0.81]$ \\
\hline \multicolumn{4}{|l|}{ Surprise } \\
\hline Carvalho et al., 2014 & 29 & 4.8 & $-0.62[-1.38,0.14]$ \\
\hline Circelli et al., 2013 & 32 & 5.7 & $-0.02[-0.72,0.67]$ \\
\hline García-Rodríguez, Fusari et al., 2009 & 32 & 3.5 & $2.08[1.20,2.96]$ \\
\hline Halberstadt et al., 2011 & 121 & 21.6 & $0.00[-0.36,0.36]$ \\
\hline Hunter et al., 2010/ Study 1 & 50 & 8.4 & $-0.67[-1.24,-0.10]$ \\
\hline Orgeta, 2010 & 80 & 15.0 & $-0.32[-0.75,0.11]$ \\
\hline Sarabia-Cobo et al., 2015 & 87 & 9.2 & $-2.06[-2.61,-1.51]$ \\
\hline Sullivan et al., 2015 & 118 & 20.7 & $-0.39[-0.76,-0.03]$ \\
\hline Suzuki and Akiyama, 2013 & 72 & 11.2 & $-1.07[-1.57,-0.58]$ \\
\hline \multicolumn{4}{|l|}{ Happiness } \\
\hline Baena et al., 2010 & 78 & 5.0 & $0.05[-0.39,0.49]$ \\
\hline Campbell et al., 2015 & 64 & 4.7 & $0.00[-0.49,0.49]$ \\
\hline Carvalho et al., 2014 & 29 & 3.3 & $0.17[-0.57,0.91]$ \\
\hline Chaby et al., 2015 & 62 & 4.6 & $-0.14[-0.64,0.36]$ \\
\hline Circelli et al., 2013 & 32 & 3.5 & $0.04[-0.66,0.73]$ \\
\hline Ebner et al., 2010 & 103 & 5.3 & $-0.29[-0.68,0.10]$ \\
\hline Ebner et al., 2012 & 60 & 4.5 & $0.37[-0.14,0.88]$ \\
\hline García-Rodríguez, Fusari et al., 2009 & 32 & 3.5 & $-0.39[-1.09,0.31]$ \\
\hline Halberstadt et al., 2011 & 121 & 5.5 & $-0.03[-0.39,0.33]$ \\
\hline Hunter et al., 2010/ Study 1 & 50 & 4.2 & $-0.42[-0.98,0.14]$ \\
\hline Krendl et al., 2010/Study 1 & 78 & 4.9 & $-0.47[-0.93,-0.02]$ \\
\hline
\end{tabular}




\begin{tabular}{lccc}
\hline \multicolumn{1}{c}{ Study } & Sample size & Weight (\%) & Effect size [95\% CI] \\
\hline Krendl et al., 2014 & 62 & 4.6 & $-0.40[-0.91,0.10$ \\
Lambrecht et al., 2012 & 33 & 2.8 & $-1.95[-2.79,-1.10]$ \\
Murphy and Isaacowitz, 2010 & 64 & 4.5 & $0.07[-0.44,0.58]$ \\
Orgeta, 2010 & 80 & 5.0 & $0.16[-0.28,0.60]$ \\
Sarabia-Cobo et al., 2015 & 87 & 5.1 & $-0.44[-0.87,-0.01]$ \\
Silver and Bilker, 2015 & 76 & 4.9 & $-0.24[-0.69,0.21]$ \\
Sullivan et al., 2015 & 118 & 5.5 & $-0.38[-0.75,-0.02]$ \\
Suzuki and Akiyama, 2013 & 72 & 4.6 & $1.07[0.58,1.57]$ \\
Svärd et al., 2012 & 39 & 3.8 & $-0.61[-1.26,0.03]$ \\
Williams et al., 2009 & 452 & 6.5 & $-0.03[-0.22,0.15]$ \\
Ziaei et al., 2017 & 40 & 3.6 & $-1.21[-1.89,-0.53]$ \\
\hline
\end{tabular}

7

8

9

10 


\section{Table 4(on next page)}

Effect of moderators on the age-related differences in emotion recognition 
1

\begin{tabular}{|c|c|c|c|c|c|c|c|}
\hline & $Q$ & $\mathrm{df}$ & $p$ & Moderator & Z & $p$ & $\beta$ \\
\hline $\begin{array}{l}\text { Anger } \\
\text { Model }\end{array}$ & 1.28 & 3 & .734 & & & & \\
\hline $\begin{array}{l}\text { Sadness } \\
\text { Model } \\
\end{array}$ & 3.09 & 3 & .377 & & & & \\
\hline $\begin{array}{l}\text { Fear } \\
\text { Model }\end{array}$ & 34.0 & 3 & .000 & $\begin{array}{l}\text { Sex }(\% F) \\
\text { Mean Years of Educat. Dif. } \\
\text { Stimulus }\end{array}$ & $\begin{array}{l}2.06 \\
4.12 \\
-1.86 \\
\end{array}$ & $\begin{array}{l}.039 \\
.000 \\
.062 \\
\end{array}$ & $\begin{array}{r}.35 \\
.78 \\
-.32 \\
\end{array}$ \\
\hline $\begin{array}{l}\text { Disgust } \\
\text { Model }\end{array}$ & 22.4 & 3 & .000 & $\begin{array}{l}\text { Sex }(\% \mathrm{~F}) \\
\text { Mean Years of Educat. Dif. } \\
\text { Stimulus }\end{array}$ & $\begin{array}{r}-2.28 \\
2.86 \\
2.40 \\
\end{array}$ & $\begin{array}{l}.023 \\
.004 \\
.016\end{array}$ & $\begin{array}{l}-.52 \\
.66 \\
.55 \\
\end{array}$ \\
\hline $\begin{array}{l}\text { Surprise } \\
\text { Model }\end{array}$ & 1.25 & 3 & .742 & & & & \\
\hline $\begin{array}{l}\text { Happiness } \\
\text { Model }\end{array}$ & 0.54 & 3 & .910 & & & & \\
\hline
\end{tabular}

3 